\title{
Die Cnidogenese der Octocorallia (Anthozoa, Cnidaria): II. Reifung, Wanderung und Zerfall von Cnidoblast und Nesselkapsel
}

\author{
H. Schmidt \& B. Moraw \\ Zoologisches Institut I der Universität Heidelberg; \\ Im Neuenheimer Feld 230, D-6900 Heidelberg, Bundesrepublik Deutschland
}

\begin{abstract}
The cnidogenesis of the Octocorallia (Anthozoa, Cnidaria): II. Maturation, migration and degeneration of cnidoblast and nematocyst. Migration of cnidoblasts has never been observed in Anthozoa. In contrast to hydrozoans, anthozoans are repeatedly reported to develop nematocysts locally without migration in the entoderm as well as in the ectoderm. The majority of the nematocysts studied in different Octocorallia species (Alcyonaria: Alcyonarium digitatum, Parerythropodium coralloides; Gorgonaria: Pseudopterogorgia aerosa; Pennatularia: Veretillum cynomorium) originate from the ectoderm of the scapus, where, however, no mature nematocysts occur. Cnidoblasts containing immature nematocysts accumulate in the distal scapus, from where they migrate singly like amoebae into the pinnulae of the tentacles. The nematocysts mature during migration, during which the capsular matrix becomes completely electron-translucent. Only in the oral disc, where few nematocysts occur, do they mature locally without migration. In the Octocorallia, nematocyst development and maturation takes places only in the ectoderm. Development of nematocysts has never been observed in the entoderm, nor in the pharynx; this demonstrates its entodermal origin. The entoderm contains only degenerated or phagocytized nematocysts. Contrary to hydrozoans, the mature anthozoan cnidocyte is rounded and has no processes to the mesogloea. Instead of a cnidocil it has a ciliary cone consisting of a normal flagellum, stereocilia and macrovilli. The cnidocyte is characterised by abundant electron-translucent cytoplasm and nematocystanchoring structures made up of cross-striated, collagen-like fibrillae and a fibrous basal ring. The position of the cross-striated fibrillae is distally similar to that of the supportive rods in hydrozoan cnidoblasts. The present study clearly demonstrates that structure and, possibly, function of an octocorallian cnidocyte is much simpler than that of a hydrozoan cnidocyte. On the other hand, cnidoblast migration, occurring in Hydrozod as well in Octocorallia, turned out to be a much older phylogenetic character than was formerly believed.
\end{abstract}

\section{EINLEITUNG}

In neuerer Zeit haben sich zahlreiche, vor allem experimentell angelegte Studien dem Problem der Nesselkapselwanderung und ihrer regulativen Mechanismen gewidmet (Hauenschild, 1957; Tardent \& Morgenthaler, 1966; Rich \& Tardent, 1969; Zumstein \& Tardent, 1971; Achermann \& Tardent, 1973; Zumstein, 1973; Carré, 1974b; Herlands \& Bode, 1974a, b; Campbell, 1974; Weber, Honegger \& Tardent, 1978; Campbell \& Marcum, 1980). In diesen ausnahmslos an Hydrozoen und vorwiegend lichtmikroskopisch durchgeführten Arbeiten zeigt nur Campbell (1974; Fig. 7) einen wandernden Cnidoblasten im Elektronenmikroskop. Zahlreiche elektronenmikroskopische Arbeiten 
beschreiben dagegen die Morphogenese (Schmidt, 1981) und/oder den reifen oder fast reifen Zustand diverser Nesselkapseln. Der Bau reifer Nesselzellen ist wiederum nur bei wenigen Hydrozoen ausführlich beschrieben worden (Slautterback, 1967; Bouillon \& Levi, 1967; Westfall, 1970), während über die Nematocyten der Anthozoen bisher nur bruchstückhaft berichtet wurde (Westfall, 1965; Ivester, 1977). Vor kurzem hat vor allem Carré (1974c) am Beispiel der Siphonophoren auf die funktionelle Einheit von Nesselkapsel und Cnidoblast hingewiesen. Diese wird bei den Hydrozoen durch die seit langem bekannte Wanderung der Cnidoblasten, während der die Nesselkapseln heranreifen, verdeutlicht (Schneider, 1900; vgl. Weill, 1934), wofür bei den Anthozoen bisher jedoch jegliche Hinweise fehlten. Nach Ivester (1977) sollen Cnidoblasten der Octocorallia lediglich lokal zur Ektodermoberfläche wandern. Auch bei den Aktinien entstehen die Nesselkapseln nach der jüngsten Feststellung von Minasian \& Mariscal (1979) am Ort ihres Verbrauches.

Demgegenüber sollen in der vorliegenden Arbeit nach der Darstellung der Cnidogenese bis zur weitgehend differenzierten Nesselkapsel (Schmidt, 1981), deren Wanderung und Reifung, die reife Nesselkapsel und Nesselzelle sowie deren Zerfall beschrieben werden. Besondere Beachtung findet dabei die Entwicklung von Cnide und Cnidoblast.

\section{MATERIAL UND METHODE}

Material: Alcyonium digitatum, Parerythropodium coralloides, Veretillum cynomorium, Pseudopterogorgia aerosa. Zur Methode siehe Teil I (Schmidt, 1981).

\section{ERGEBNISSE}

Lichtmikroskopisch lassen sich die Nesselkapseln der Octocorallia in fast allen Körperpartien nachweisen. Allerdings ist der Nesselkapselbesatz und -zustand höchst unterschiedlich. Die Masse der nicht färbbaren, reifen Nesselkapseln sitzt in den Pinnulae der Tentakeln (Abb. 1). Intensiv färbbare, unreife Stadien finden sich stellenweise dicht gedrängt vorzugsweise im Ektoderm des distalen Scapus (Abb. 1, 1a) und, weit weniger häufig, in dem der Mundscheibe. Im Entoderm sind Nesselkapseln nur selten in größerer Anzahl anzutreffen. Die elektronenmikroskopische Untersuchung hat ergeben, daß sich die in Teil I beschriebene Entwicklung (Sekretion und Differenzie-

Abb. 1. Längsschnitt durch einen Polypen: T: Tentakelanschnitte (Pinnulae), M: Mundscheibe, $P$ : Pharynx, S: Scapus, D: Nesselkapseldepot (vgl. 1a). Färbung: Toluidin. Alcyonium digitatum, $204 \times$

Abb. 1a. Nesselkapseldepot im Ektoderm des distalen Scapus. Alcyonium digitatum, $230 \times$ Abb. 2. Scapusanschnitt längs: En: Entoderm mit degenerierter Nesselkapsel (von elektronendichter Masse umgeben, Pfeil), M: Mesogloea, Ek: Ektoderm mit fortgeschrittenen Sekretionsstadien zwischen der Muskulatur; an der Oberfläche differenzierte Stadien in kollabiertem Zustand. Pfeil:

Epithelzelle (undifferenzierter Cnidoblast?). Parerythropodium coralloides, $3200 \times$

Abb. 3. Übergang Mundscheibe - Pharynx (Pfeil: Grenze). Man beachte die abrupte Unterbrechung der Cnidogenese und die unterschiedlich langen Mikrovilli. Typisch für die Mundscheibe: Vorkommen von Genesestadien unter den reifen Nesselkapseln; En: Entoderm. Alcyonium digitatum, $2500 \times$ 


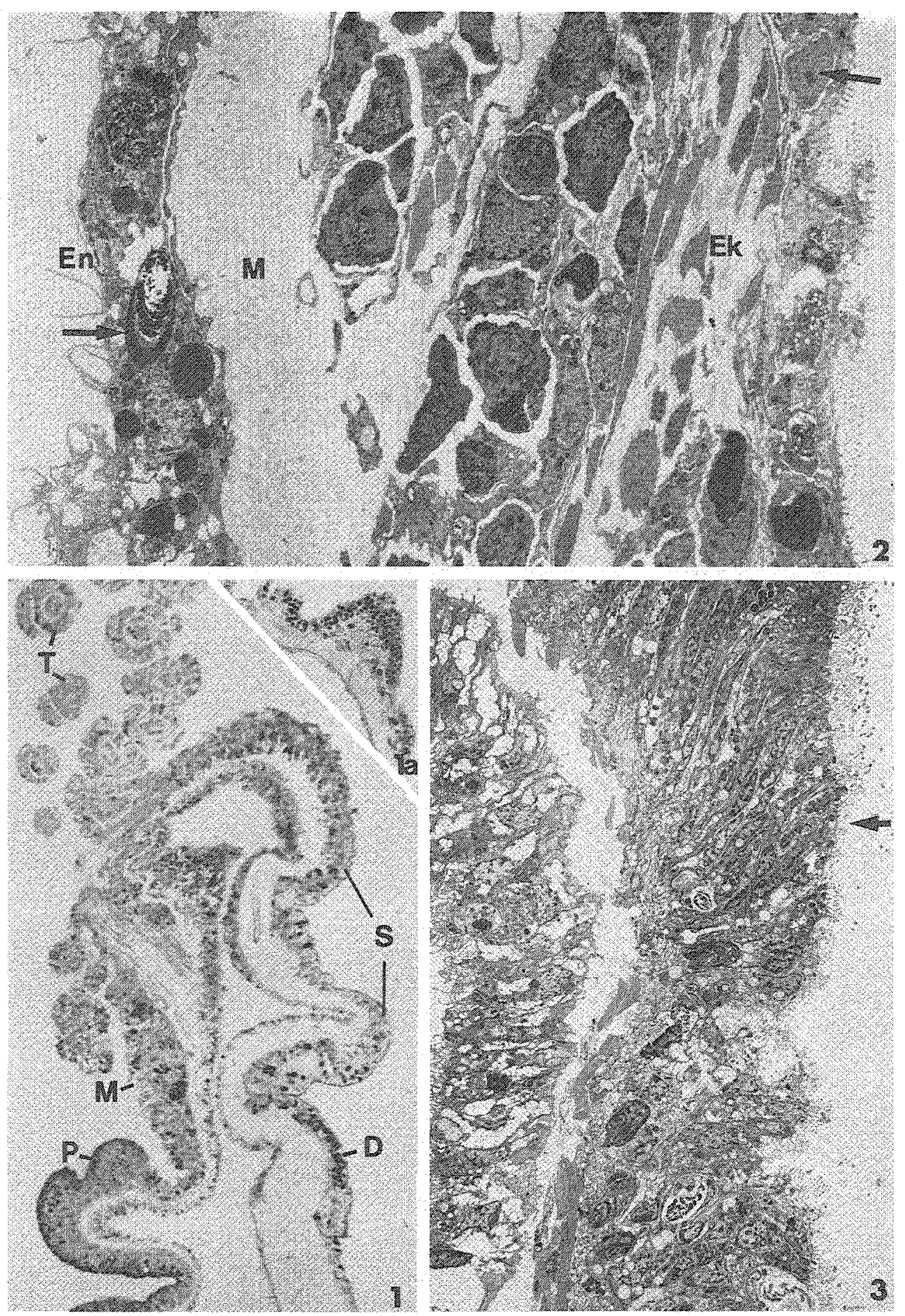


rung) im Ektoderm des Scapus und vereinzelt im Ektoderm der Mundscheibe abspielt (Abb. 2, 3). Die lichtmikroskopisch im Entoderm nachgewiesenen Nesselkapseln erwiesen sich im Elektronenmikroskop ausnahmslos als degeneriert (Abb. 2, 23, 24).

\section{Wanderung und Reifung}

Im gesamten Scapus kommen keine reifen Nesselkapseln vor. Die Matrix sämtlicher hier anzutreffender Nesselkapseln ist elektronendicht (Abb. 2). Dagegen entsteht die Masse der Nesselkapseln in dieser Region, und zwar nahe der Mesogloea zwischen den ektodermalen Muskellagen (Abb. 2). Die Kerne der in Sekretion begriffenen Cnidoblasten haben einen Nucleolus und ungleichmäßig kondensiertes Chromatin. Das Cytoplasma enthält reichlich rauhes endoplasmatisches Reticulum und Ribosomen. Diesem cytologischen Befund entsprechend befinden sich die Nesselkapseln im Stadium der Außenschlauchsekretion bzw. der primären Kapselwanddifferenzierung (Abb. 2; vgl. Schmidt, 1981). Trotz einer weitgehend synchronen Entwicklung und reichlich vorhandener Zellausläufer konnten in keinem Fall typische interstitielle Zellen, Teilungsstadien oder Zellbrücken beobachtet werden.

Nahe der Oberfläche des Scapusektoderms befinden sich distal (Abb. 4) zunehmend ausschließlich Nesselkapseln mit bereits angelegtem Innenschlauch. Die meisten dieser Nesselkapseln zeigen noch Anzeichen des kurz nach der Einlagerung des Schlauches kollabierten Zustandes, in dem die typische asymmetrische Verjüngung des distalen Kapselendes auftritt. Seitlich neben diesem spitz auslaufenden Kapselende werden einzelne quergestreifte Fibrillen sichtbar, die sich zur Nesselkapsel hin stempelartig verbreitern (Abb. 20). Das endoplasmatische Reticulum dieser Cnidoblasten ist erheblich reduziert, obgleich Ribosomen noch reichlich vorhanden sind. Die Interzellularspalten sind relativ eng (Abb. 4). Weiter distal sind schließlich, meist in größeren Mengen in einem verdickten Ektoderm liegend, nur noch rundliche, weitgehend differenzierte, aber noch unreife Nesselkapseln anzutreffen (Abb. 1, 1a, 5). Thre Cnidoblasten sind durch eine starke Reduktion des Cytoplasmas gekennzeichnet, das zahlreiche Vakuolen aufweist (Abb. 5). Entsprechend groß sind die Interzellularspalten. Cnidoblasten mit derart reduziertem Cytoplasma sind bereits in der Lage, die typischen von Stereocilien umgebenen Flagellen der Anthozoennesselzellen zu bilden (Abb. 6). Im Bereich des Flagellums, das sich, wie die Centriolen früherer Stadien, stets in der Nähe der Kapselöffnung befindet, geht der Cnidoblast eine besondere Verbindung (Abb. 6) mit

Abb. 4. Ansammlung von Cnidoblasten mit kollabierten Nesselkapseln, unmittelbar nach der Schlaucheinlagerung (vgl. Abb. 20). Parerythropodium coralloides, $4700 \times$

Abb. 5. Nesselkapseldepot: Cnidoblasten mit weitgehend differenzierten, aber noch unreifen Nesselkapseln, starke Reduktion des Cytoplasmas. Alcyonium digitatum, $6000 \times$

Abb. 6. Cnidoblast aus dem Nesselkapseldepot in engem Kontakt (Zonulae adhaerentes) mit einer

Nachbarzelle im Bereich des Flagellums. S: Stereocilien. Alcyonium digitatum, $17500 \times$

Abb. 7. Wandernder Cnidoblast: Kapsel mit Falte (Pfeil) und aufgehellter Kapselmatrix. Schaft- (S) und Fadenregion (F) deutlich zu unterscheiden (Schaft mit Dornen). Am Offnungspol quergestreifte, parallel verlaufende Fibrillen (Pfeil), Centriol (Pfeil). Alcyonium digitatum, $11800 \times$

Abb. 8. Wandernder Cnidoblast (Tentakel): Cytoplasma und Kapselmatrix aufgehellt. Am Öffnungspol (Schaftregion) quergestreifte Fibrillen mit quergestreiftem Ligament (L) als Teil des Centriolenkomplexes (s. Abb. 10, 13, 14). Alcyonium digitatum, $13300 \times$ 

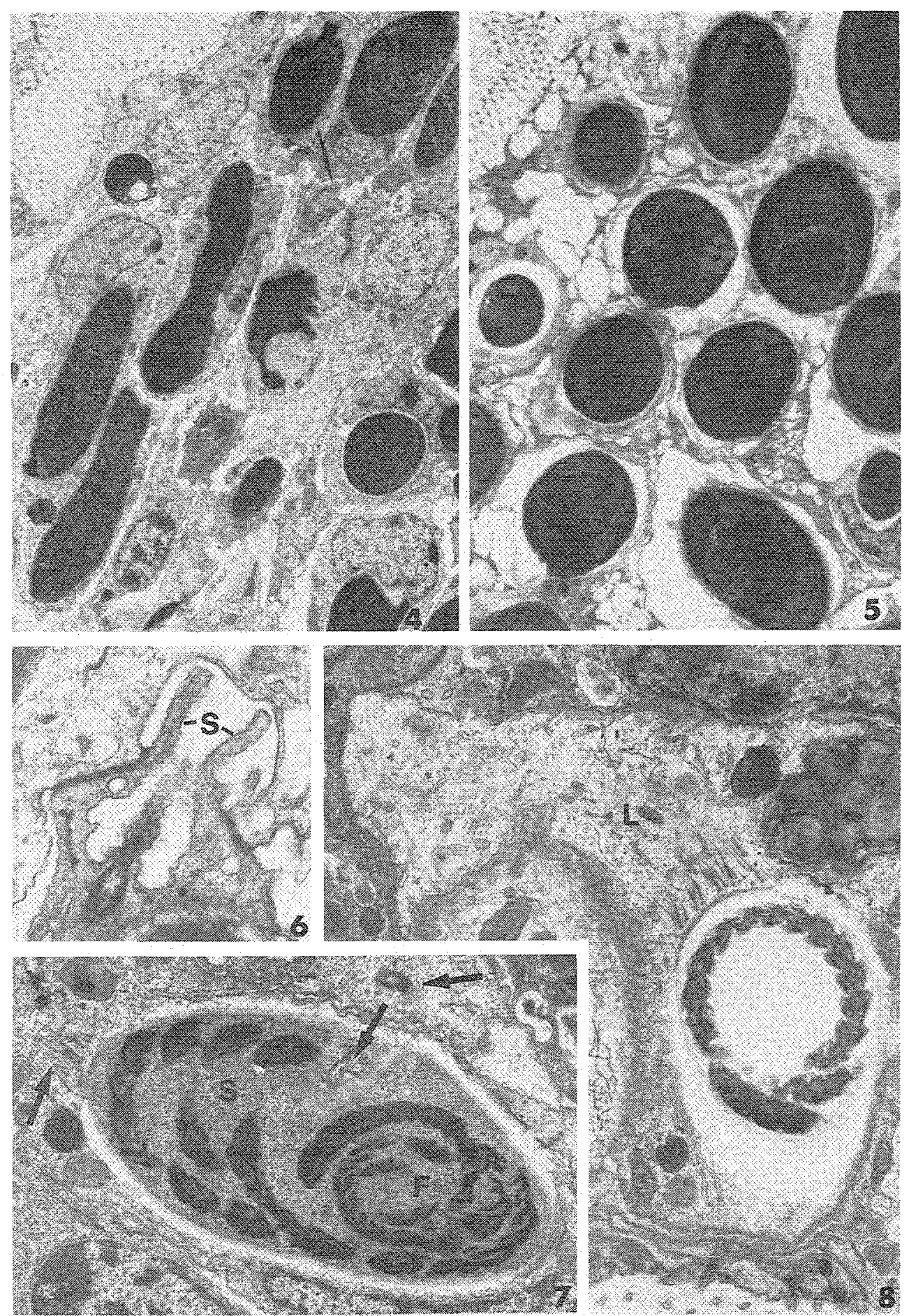

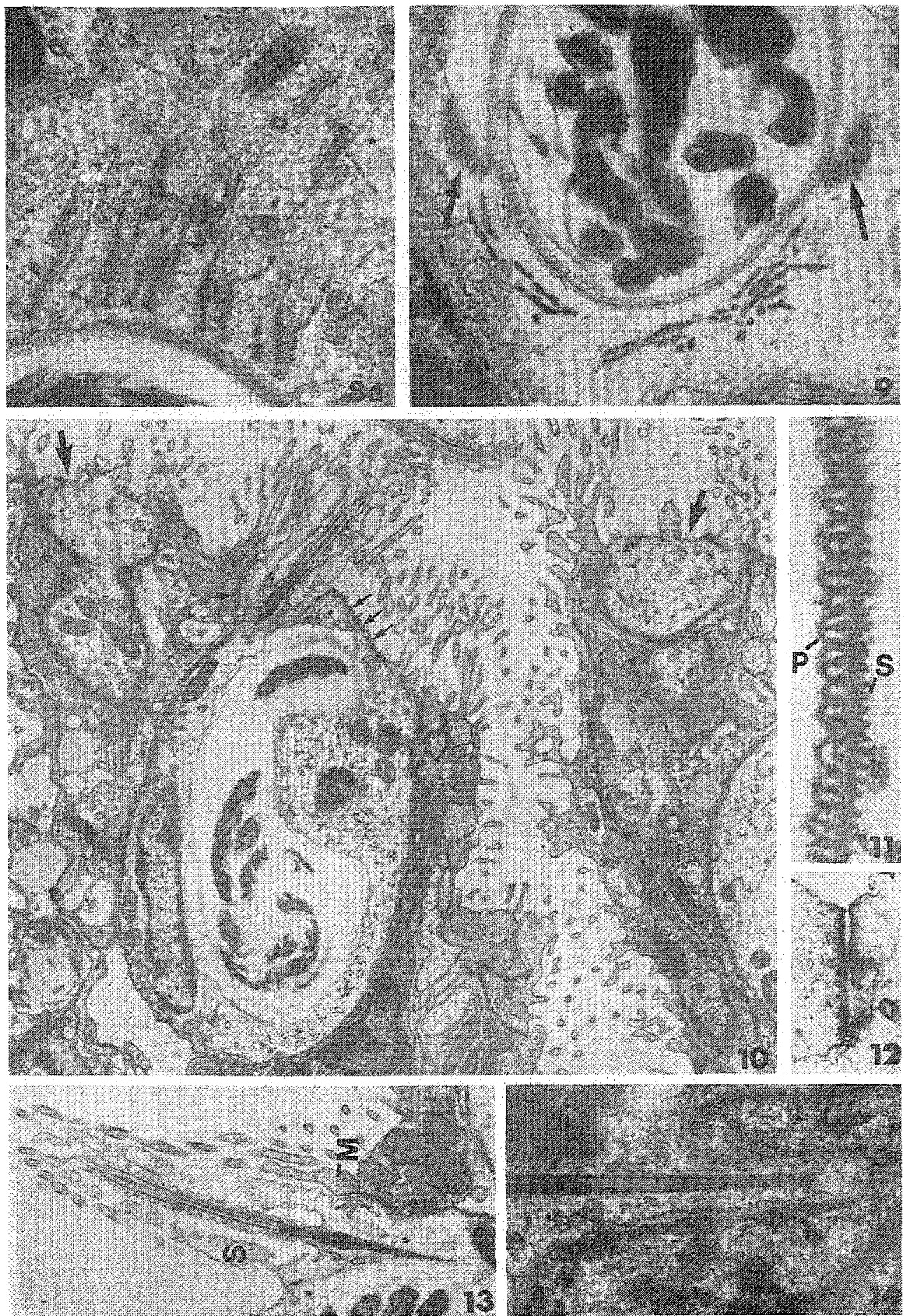

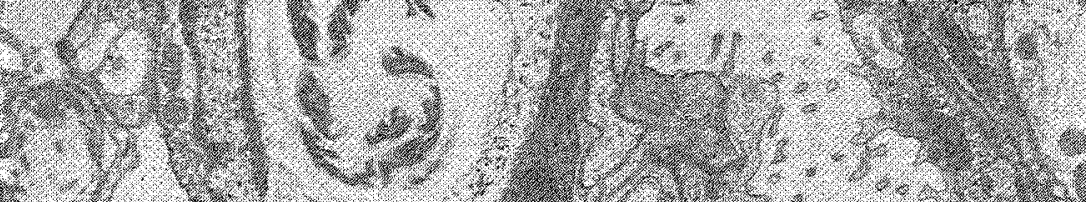
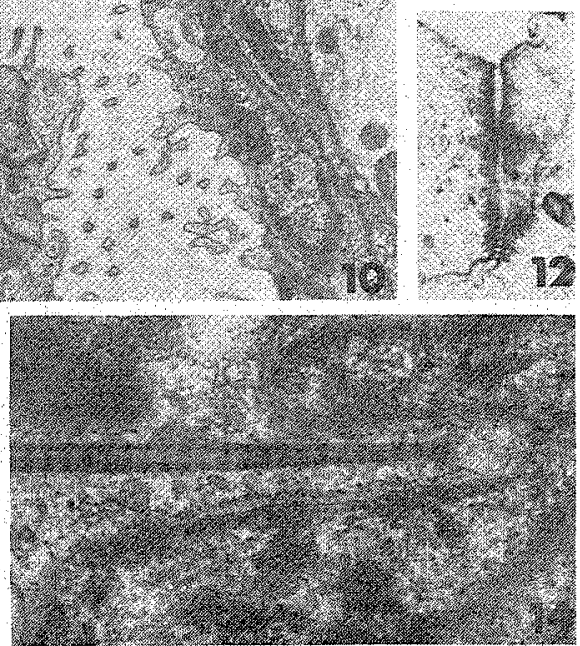
einer oder mehreren Nachbarzellen ein, die, da noch weitgehend unseptiert, als Zonula adhaerens zu bezeichnen ist. Der Kern liegt meist am entgegengesetzten Ende der bis dahin nicht weiter veränderten Nesselkapsel. Mitunter gelangen einzelne, derart entwickelte Cnidoblasten an der Oberfläche des Ektoderms in eine Position, die dem reifen Zustand entspricht, ohne sich allerdings weiterzuentwickeln. Im Gegensatz zu den in Scapus und Tentakeln unterschiedlich lokalisierten Stadien enthält das Ektoderm der Mundscheibe an seiner Basis mehr über als zwischen den Muskelfortsätzen einzelne verschiedene Entwicklungsstadien und an seiner Oberfläche reife Nesselkapseln mit elektronenlichter Matrix (Abb. 3).

Die weitere Entwicklung erfolgt im obersten Teil des Scapus und in den Tentakeln und ist wie in der Mundscheibe nur an einzelnen Cnidoblasten zu verfolgen. Die Matrix der Nesselkapseln dieser offensichtlich zu den entfernten Tentakelbereichen bzw. zur Oberfläche der Mundscheibe wandernden Cnidoblasten wird, mit Ausnahme des Innenschlauches, allmählich aufgehellt, d. h. sie wird zunehmend elektronendurchlässig (Abb. 7, 8). Die Aufhellung erstreckt sich auch auf den Inhalt der tunnelartigen Strukturen der Propria (vgl. Abb. 9, 11, 20 und Schmidt, 1981). Seitlich um die Nesselkapsel entsteht mit zunehmender Matrixaufhellung ein elektronenlichter Hof (Abb. 7, 9, 10, 15, 16, 22). Lediglich an der Basis und am Offnungspol behält die Nesselkapsel ihren unmittelbaren Kontakt mit der umgebenden Membran bzw. mit dem Cytoplasma (Abb. $7,8,9,22)$. Im Bereich der Kapselöffnung sind stets einzelne Elemente des Centriolenkomplexes in Form von Centriolen oder quergestreiftem Ligament zu erkennen (Abb. 7 , 8). Am gleichen Kapselende sind zunehmend schopfartig angeordnete quergestreifte Fibrillen zu erkennen, die sich an ihrem schmalen Ende in schweifartig in das Cytoplasma ausstrahlende Einzelelemente auflösen (Abb. 7, 8, 8a). Mit aufhellender Nesselkapselmatrix wird das Cytoplasma wieder voluminöser und ebenfalls elektronenlichter (vgl. Abb. 7, 8, 10). Neben Resten des rauhen endoplasmatischen Reticulums treten zunehmend Elemente des glatten endoplasmatischen Reticulums und mäßig elektronendichtes Material auf (Abb. 7, 8). Die Form der Cnidoblasten ist polymorph und

Abb. 8a. Ausschnitt aus Abb. 8: Schweifartige Fortsätze der quergestreiften Fibrillen am Öffnungspol der Nesselkapsel, quergestreiftes Ligament. Alcyonium digitatum, $30800 \times$

Abb. 9. Reifer Cnidoblast mit quergestreiften Fibrillen an der Basis der Nesselkapsel, fibröser Ring (Pfeile). Alcyonium digitatum, $30000 \times$

Abb. 10. Pinnula längs mit gerade eingewandertem Cnidoblasten (Nesselkapsel noch eingedellt): terminal verdickte Enden der radiär angeordneten, quergestreiften Fibrillen (3 Pfeile); typisches, von Stereocilien umstandenes Flagellum, Pfeil: Lage der septierten Desmosomen (vgl. Abb. 12): rechts und links "leere" Cnidoblasten mit quergestreiften Fibrillen (Pfeil rechts) und Krater (Pfeil links). Alcyonium digitatum, $9100 \times$

Abb. 11. Wandstruktur der reifen Nesselkapsel: Rillen der Sklera (S) und Tunnelstruktur der Propria mit pfeilartigen Stützen (P). Veretillum cynomorium, $192500 \times$

Abb. 12. Septiertes Desmosom zwischen Cnidoblast und Ektodermzelle (vgl. Abb. 10). Alcyonium digitatum, $43400 \times$

Abb. 13. Ciliarkonus des reifen Cnidoblasten: Zentral Flagellum mit normalem Axialzylinder und

Centriolenkomplex mit quergestreiftem Ligament, S: Stereocilien der Nematocyte, M: Makrovilli einer Nachbarzelle mit dichterem Inhalt (vgl. Abb. 18, 19). Alcyonium digitatum, $10500 \times$

Abb. 14. Quergestreiftes Ligament des Centriolenkomplexes, in einer Kernnïsche endend. Alcyonium digitatum, $25500 \times$ 


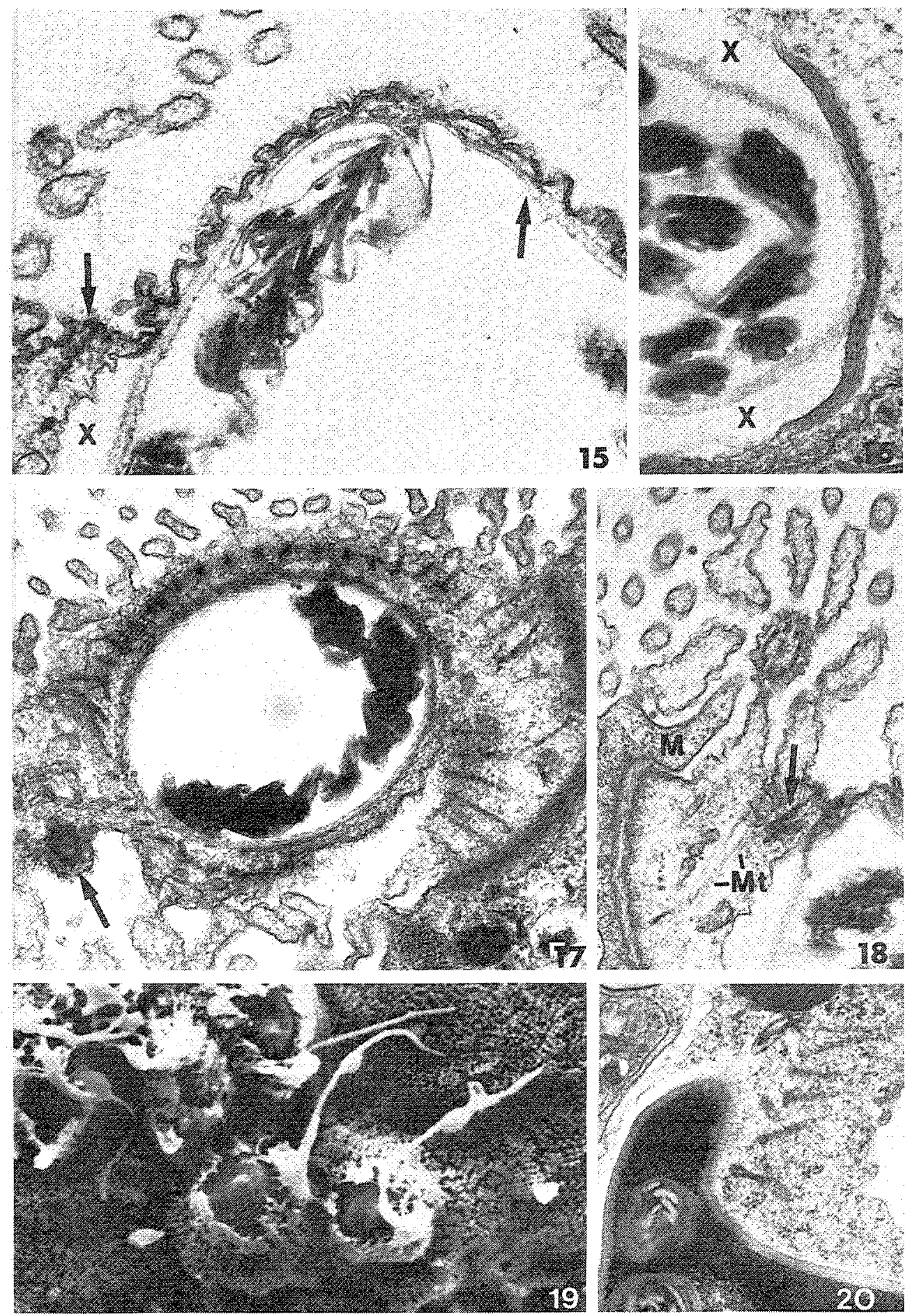


insbesondere an den Basen der Pinnulae durch pseudopodienartige Ausläufer gekennzeichnet (Abb. 8).

\section{Der reife Cnidoblast und die feuerbereite Cnide}

Der reife Cnidoblast hat demgegenüber, sowohl in der Mundscheibe als auch in den Tentakeln, wo er massenhaft vor allem Bestandteil der häufig rein ektodermalen Pinnulae ist, eine auffallend abgerundete oder ovale Form (Abb. 10, 21, 22, 25). Er ist mit den benachbarten Ektodermzellen an der Oberfläche durch septierte Desmosomen verbunden (Abb. 10, 12, 25). Das Cytoplasma ist, gegenüber den normalen Ektodermzellen, auffallend elektronenlicht, jedoch keineswegs arm an Organellen und Strukturen. Der Kern ist praktisch unverändert. Nucleoli sind allerdings nicht mehr nachweisbar. Neben den normalen Organellen wie Golgiapparat und Mitochondrien kommen einige unbekannte Einschlüsse und in größerem Umfang lipidartige Kugeln vor. Das glatte endoplasmatische Reticulum tritt gegenüber dem rauhen verstärkt hervor. Das Besondere der reifen Cnidoblasten sind jedoch neben der Nesselkapsel die inneren, cnidenverankernden und äußeren Begleitstrukturen. Die reife, feuerbereite Nesselkapsel liegt in meist abgerundeter, länglich-ovaler Form vor. Ihr Inhalt (Matrix) ist, bis auf den Schlauch, vollkommen elektronentransparent (Abb. 10, 22), wodurch die Struktur der Kapselwand besonders deutlich hervortritt. Auch in der reifen Cnide sind die Tunnelstruktur der Propria und die Rinnenstruktur der Sklera wie in den Entwicklungsstadien winklig zueinander angeordnet und dadurch nur selten auf einem Schnitt zu beobachten (Abb. 9, 11). Die Wand des Schlauches ist noch dünner als das Übergangsstück und weist mit ihrer starken Faltung auf eine verstärkte Schlauchverdichtung, die auch in den dicht gepackten Dornen zum Ausdruck kommt (Abb. 8, 10, 15, vgl. Schmidt 1981: Abb. 21, 22). In den reifen Nesselkapseln sind in der völlig elektronentransparenten Matrix die einzelnen Schlauchabschnitte, der basale Schaft und der terminale Faden, deutlich an ihrer unterschiedlichen Lage, Querschnitt und Bedornung zu unterscheiden (Abb. 10,

Abb. 15. Offnungspol der feuerbereiten Nesselkapsel, von "nackter" Zellmembran bedeckt (vgl. Abb. 19), Pfeil: Ende der typischen Kapselstruktur resp. Beginn des dünnwandigen Übergangsstükkes, typische Position der quergestreiften Fibrillen (Pfeil), X: Raum zwischen Nesselkapsel und Membran. Alcyonium digitatum, $44000 \times$

Abb. 16. Fibröser Ring um die Nesselkapselbasis (Schrägschnitt durch reifen Cnidoblasten), X: Raum zwischen Nesselkapsel und Membran. Alcyonium digitatum, $40150 \times$

Abb. 17. Radiär angeordnete, quergestreifte Fibrillen am distalen Kapselpol, Pfeil: Flagellenbasis außerhalb des Fibrillenkranzes. Alcyonium digitatum, $21000 \times$

$\mathrm{Abb}, 18$. Ciliarkonus mit zentralem Flagellum, umgeben von 7 Stereocilien, $\mathrm{M}$ : Makrovillus einer Nachbarzelle mit dichterem Inhalt, Mt: Mikrotubuli an der Basis der Stereocilien, Pfeil: quergestreifte Fibrillen. Alcyonium digitatum, $21000 \times$

Abb. 19. Tentakeloberfläche mit Mikrovilli, feuerbereiten Cniden und Ciliarkonus; zentrale Vorwölbung der Nesselkapseln möglicherweise Artefakte. $27500 \times$

Abb. 20. Nesselkapsel in kollabiertem Stadium (entsprechend Abb. 4) mit typisch verjüngtem Öffnungspol, Matrix auch innerhalb der Propriastruktur noch elektronendicht (vgl. Abb. 11), seitlich erste quergestreifte Fibrillen. Pseudopterogorgia aerosa, $31500 \times$ 
vgl. 7). In der reifen Kapsel bleibt die Schlauchmatrix größtenteils elektronendicht (Abb. 10, 21, 22). Die Dornen sind dagegen von Anfang an nur mäßig elektronendicht (Abb. 8, $10,20)$. Auch in der reifen Nematocyte ist die Nesselkapsel stets von einem elektronenlichten Hof umgeben, der die Membran seitlich von der Nesselkapsel abhebt (Abb. 15, 16, 22). Die Nesselkapsel ist lediğlich proximal und distal im Cytoplasma verankert. Die proximale Verankerung besteht in einem auffallenden, fibrösen Ring (Abb. 9, 16, 22), der die Basis der Nesselkapsel umgibt und den elektronenlichten Hof basal begrenzt (Abb. 9, 16, 25). Im Gegensatz zum wandernden Cnidoblasten wird in der reifen Nematocyte auch die Nesselkapselbasis von allerdings weniger geordnet verlaufenden quergestreiften Fibrillen begleitet (Abb, 9, 10, 22), die anfangs auch seitlich neben der Nesselkapsel vorkommen (Abb. 10, 21). Die in der Wanderphase am Óffnungspol der Nesselkapsel schopfartig angeordneten, quergestreiften Fibrillen umgeben in der reifen Nesselzelle radiär den über das Ektoderm herausragenden Öfnungspol der Nesselkapsel (Abb. 10, 17, 25). Thre terminalen Verdickungen nehmen dabei seitlich neben der Nesselkapsel Kontakt mit der freien Zellmembran auf (Abb. 15, 18). Apikal ist die Nesselkapsel lediglich von glatter Zellmembran bedeckt, der Cilien oder Mikrovilli fehlen (Abb. 15, 19). Diese sind dagegen verstärkt an der Peripherie der Nesselkapsel ausgebildet. Die auffälligste äußere Erscheinung ist der dem Cnidocil der Hydrozoen entsprechende Ciliarkonus (Abb. 10, 13, 18, 19, 25), dessen zentrales Element ein normales Flagellum, bestehend aus einem $9+2$-Axialzylinder, darstellt (Abb. 18). Das in einer leichten Vertiefung entspringende Flagellum (Abb. 10) wird von 7 Stereocilien der eigenen Nematocyte und von weiteren Makrovilli umstanden, die vorwiegend von den angrenzenden Ektodermzellen gebildet werden (Abb. 13, 18). Die Makrovilli der Nachbarzellen unterscheiden sich von den Stereocilien der Nematocyte durch den geringeren Querschnitt und etwas elektronendichteren Inhalt (Abb. 13). Das Flagellum entspringt einem Centriolenkomplex, wie er in sämtlichen flagellentragenden Epithelzellen vorkommt (Abb. 10, 13,14). Der Unterschied zu einem "primären Centriolenkomplex" (vgl. Teil I) besteht lediglich in dem beim Centriolenkomplex reifer Cnidoblasten offenbar fehlenden Satelliten. Dennoch sind in der Nähe des Centriolenkomplexes zahlreiche Mikrotubuli zu beobachten, die zur Basis der Stereocilien streben (Abb. 18, 25). Im Innern setzt sich der Centriolenkomplex des offenbar stets auf der Seite des Nematocytenkernes gebildeten Ciliarkonus (Abb. 10, 13, 14, 22) mit einem langen, quergestreiften Ligament fort, das, wie in einem Fall beobachtet, sich terminal leicht

Abb. 21. Pinnulae der Tentakeln mit rundlichen, reifen Cnidoblasten, Cnidoblastenersatz an der Spitze (vgl. Abb. 22), Pfeil: leerer Cnidoblast, V: möglicherweise ehemaliger Sitz eines Cnidoblasten. Alcyonium digitatum, $4800 \times$

Abb. 22. Reife Cnidoblasten mit feuerbereiten Cniden an der Spitze der Pinnulae. Alcyonium digitatum, $5200 \times$

Abb. 23. Degenerierte Nesselkapseln im Entoderm (Tentakel) nach Temperaturstreß (Pfeile), Mesogloea (M), intakte Nesselkapseln mit elektronenlichter Matrix im Ektoderm (x). Alcyonium digitatum, $4300 \times$

Abb. 24. Fortgeschrittener Abbau einer Nesselkapsel (Tentakelentoderm); innere Strukturen weitgehend aufgelöst. Alcyonium digitatum, $17250 \times$

Abb. 24a. Weitgehend abgebaute Nesselkapsel; innere Strukturen, einschließlich Propriastrukturen, aufgelöst (Pfeil: glatte Innenwand); lediglich Sklerastruktur (parallel verlaufende, äußere Rillen: vgl. Teil I Schmidt, 1980, Abb. 13) erhalten. Alcyonium digitatum, $61200 \times$ 

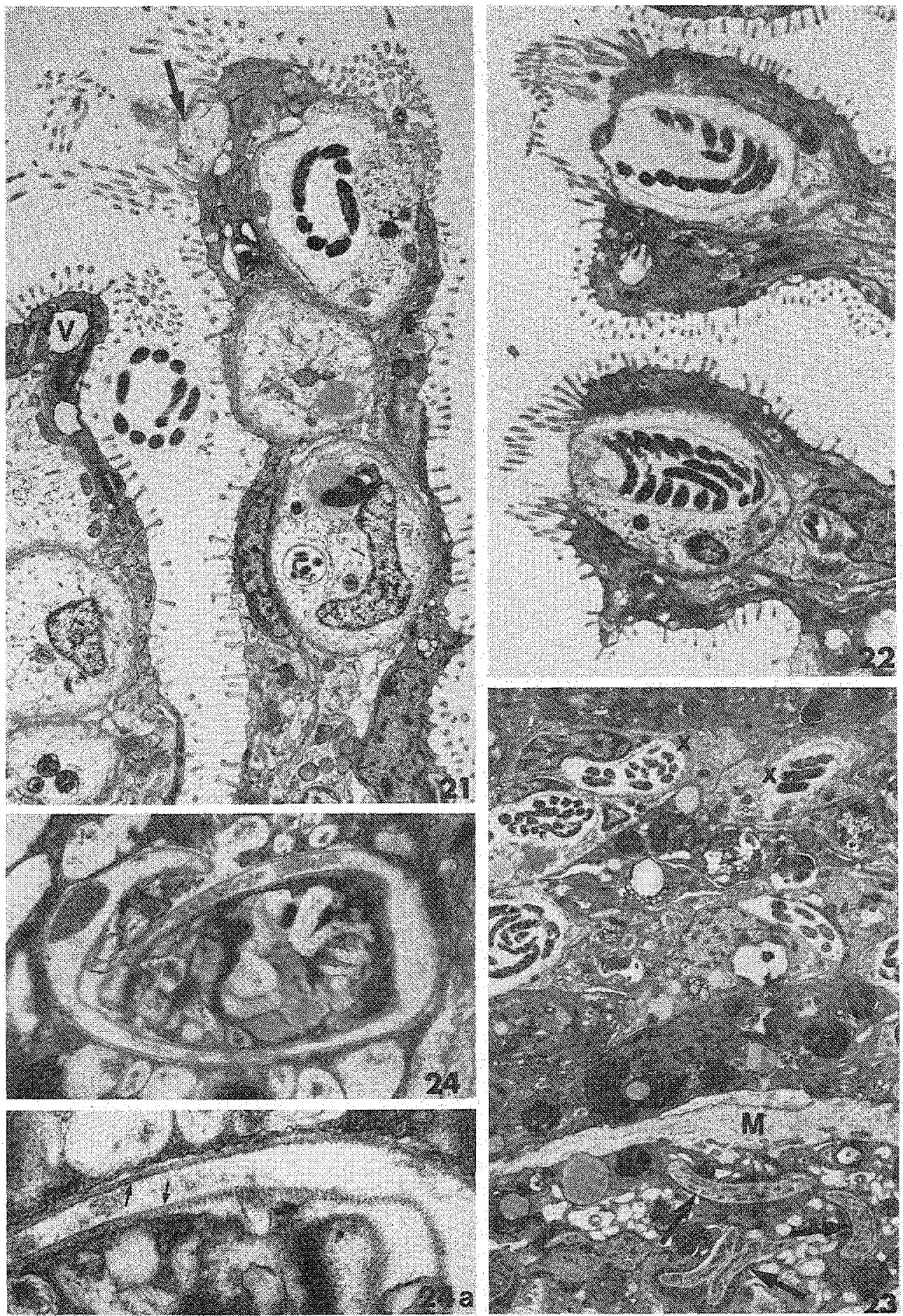
verbreiternd, einer Einbuchtung des Kernes entspringt. Die hier beschriebenen reifen Cnidoblasten bringen ihre Nesselkapseln in den Apikalpositionen der Tentakel, an der Spitze der Pinnulae in Stellung, wo offenbar die meisten Cniden abgefeuert bzw. verbraucht werden. Die Pinnulae sind angefüllt mit reifen Cnidoblasten, die anscheinend nur darauf warten, den Platz der obersten Nematocyte einzunehmen (Abb. 10, 21).

\section{Der Zerfall}

Nach Abschuß der Cnide bleibt von der Nematocyte nur wenig übrig. Die anfangs einen tiefen Krater aufweisende "verbrauchte" Nesselzelle wird offenbar durch nachrückende Cnidoblasten rasch zur Seite gedrängt, wo schließlich nur noch Reste von Nematocyten mit quergestreiften Fibrillen zu erkennen sind (Abb. 10, 21). Die verbrauchten Cnidocyten werden offenbar abgestoßen, wobei die vergrößerten Mikrovilli der Nachbarzellen erhalten bleiben. In keinem Fall konnten im Ektoderm der Octocorallia-Polypen sich regenerierende oder degenerierte Cnidoblasten beobachtet werden.

Ein ganz anderes Bild bietet das Entoderm, insbesondere nach transportbedingtem Streß durch Sauerstoffmangel und unnatürlicher Temperaturerhöhung. Im gesamten Entoderm kommen normalerweise keine auch nur annähernd den reifen Cnidoblasten gleichenden Zellen vor. Die vereinzelt im Entoderm vorkommenden Nesselkapseln sind zwar differenziert (Innenschlauch), jedoch ausnahmslos degeneriert. Darauf weisen die der Nesselkapsel anliegende elektronendichte Masse und die Position der Nesselkapseln hin, die kaum auf ihre funktionsgerechte Verwendung schließen läßt (Abb. 2). Die Mesogloea der Octocorallia-Polypen ist stellenweise unterbrochen, und das Entoderm, insbesondere der Tentakeln, enthält zahlreich degenerierte Nesselkapseln (Abb. 23). In den "gestreßten" Polypen konnten diese massenhaft beobachtet werden. In stark vakuolären Zellen gelegen und häufig von elektronendichtem Material umgeben, lassen die gekrümmten und geschrumpften Nesselkapseln nur noch wenig von ihrem Inhalt und meist nur Strukturen ihrer Kapseln und Dornen erkennen. Bald danach sind die Nesselkapseln flach ausgezogen und in sich gefaltet (Abb. 24), inmitten von fibrösem Material oder elektronendicht umrandetem Lipid zu finden. Der Kapselinhalt ist elektronenlicht oder fein granuliert. Von der Kapselwand überdauert am längsten die Sklera. Derart degenerierte Kapseln zeigen nicht die typische Wandstruktur intakter Kapseln, sondern lediglich die parallel verlaufenden Sklerarillen, die allein nach der primären Kapselwanddifferenzierung zu beobachten sind, wenn die Strukturen der Propria noch nicht ausgebildet sind (Abb. 24a: vgl. Schmidt 1981, Abb. 12).

\section{DISKUSSION}

Die vorliegenden Befunde haben für die Anthozoen, vor allem am Beispiel von verschiedenen Alcyonarien, den ersten Nachweis der Cnidoblastenwanderung erbracht, die, von Hydrozoen bereits seit langem bekannt (u. a. Schneider, 1900), auch heute noch Thema zahlreicher Arbeiten ist (vgl. "Einleitung"). Bei den Vertretern anderer Octocorallia-Ordnungen, bei Pseudopterogorgia aerosa (Gorgonaria) und Veretillum cynomorium (Pennatularia), weist eine ähnliche Verteilung der verschiedenen Nesselkapselstadien ebenfalls auf eine Cnidoblastenwanderung hin. Übereinstimmend entsteht die Masse der Nesselkapseln bei Octocorallia wie Hydrozoa nicht am Ort ihres Einsatzes, 


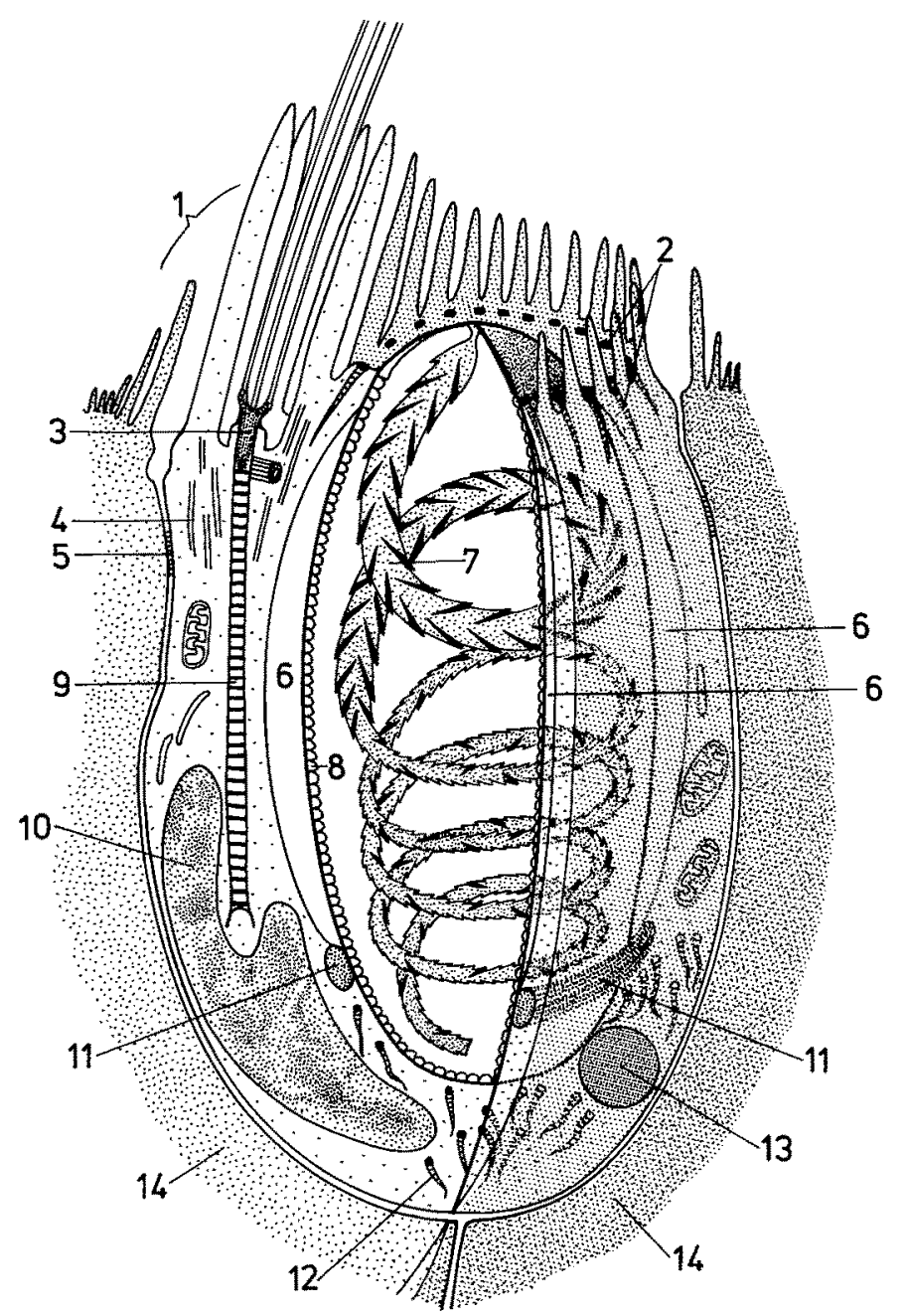

Abb. 25. Reifer Cnidoblast einer Octokoralle (halbschematisch, links geöffnet): (1) Ciliarkonus (median geschnitten), bestehend aus, von außen nach innen: Makrovilli (einschließlich der von anliegenden Zellen), Stereocilien und Flagellum; (2) distaler Kranz von quergestreiften Fibrillen; (3) Centriolenkomplex; (4) Mikrotubuli; (5) septiertes Desmosom; (6) elektronenlichter Hof um die Nesselkapsel; (7) Schaftteil des Nesselschlauches; (8) tunnelartig strukturierte Innenwand der Nesselkapsel (Propria); (9) quergestreiftes Ligament; (10) Kern; (11) fibröser Ring; (12) proximale quergestreifte Fibrillen; (13) Lipidkugel; (14) benachbarte Ektodermzellen; auBerdem Ausschnitte von Mitochondrien und glattem endoplasmatischem Retikulum

sondern im Ektoderm von Scapus bzw. Stolonen. Damit ist die Behauptung, bei den Anthozoen gäbe es keine Cnidoblastenwanderung, da bisher nicht bêobachtet (u. a. Moroff, 1909; Yanagita \& Wada, 1959; Minasian \& Mariscal, 1979), zumindest für die Octocorallia widerlegt. Im allgemeinen wandern die Cnidoblasten nur vom Scapus in die Tentakel, während sie an Orten mit schwächerem Nesselkapselbesatz, wie in der 
Mundscheibe, auch lokal am Einsatzort entstehen können. Die entwicklungsphysiologische Problematik, die sich hinter diesem Befund verbirgt, ist unseres Erachtens von den Experimentalforschern (s. "Einleitung") viel zu wenig in Betracht gezogen worden und soll daher einer anderen Arbeit vorbehalten bleiben. An dieser Stelle soll der strukturelle Vergleich mit den bisher vor allem an Hydrozoen erhobenen Befunden im Vordergrund stehen.

\section{Die frühen Cnidoblasten}

Wie von den älteren Autoren für die Hydrozoen beschrieben, entwickeln sich die Nesselkapseln und Cnidoblasten der Octocorallia (Abb. 2) "in der Tiefe der Muskelfalten" (Kühn, 1914-1916). Nach neueren Untersuchungen soll jedoch bei Hydra die frühe Entwicklung an der Ektodermoberfläche erfolgen und die "fast reifen Nematoblasten" in der Nähe der Mesogloea liegen (Campbell, 1974), wo die Fortsätze der Epithelmuskelzellen angeblich der Kontaktführung wandernder Cnidoblasten dienen (Campbell \& Marcum, 1980). Die Entwicklung von Cnidoblasten aus interstitiellen Zellen wurde bisher elektronenmikroskopisch noch nicht einwandfrei dargestellt (Lentz, 1965), da die Nesselkapselanlage erst auf einem relativ späten Stadium zu erkennen ist (Schmidt, 1981). Sie ist nach den vorliegenden Befunden bei Anthozoen unwahrscheinlich, da weder typische interstitielle Zellen noch irgendwelche Zellteilungsstadien zwischen den Cnidoblasten oder innerhalb des übrigen Ektoderms beobachtet werden konnten. Bei den Anthozoen - und nach den Ausführungen Campbells (1974) möglicherweise auch bei anderen Cnidaria - gewinnt die Möglichkeit der direkten Umwandlung von normalen Epitheloberlfächenzellen zu Cnidoblasten aufgrund unserer Untersuchungen an Anthozoenoocyten (Schäfer \& Schmidt, 1982), die unmittelbar, also ohne den Umweg über interstitielle Zellen aus normal differenzierten entodermalen Oberflächenzellen hervorgehen, immer mehr Bedeutung und Wahrscheinlichkeit. An der Scapusoberfläche der Octocorallia konnten wir jedenfalls hin und wieder die gleichen Oberflächenzellen beobachten (Abb. 2), die durch ein schwach kondensiertes Kernchromatin und einen starken Nucleolus auffallen und im Entoderm Gameten bilden. Besondere cytoplasmatische Differenzierungen sind in diesen Zellen nicht zu beobachten.

Die jungen, sekretorisch aktiven Cnidoblasten zeigen dagegen das typische cytologische Bild mit rauhem endoplasmatischen Reticulum und Vesikel produzierendem Golgiapparat (Slautterback \& Fawcett, 1959; Westfall, 1965; Skaer, 1973; Holstein, 1981). Obwohl nahezu in allen Muskeltaschen Cniden und Cnidoblasten auffallend einheitlich entwickelt waren, wurden zwar reichlich Zellausläufer, nicht jedoch die von Slautterback \& Fawcett (1959), Slautterback (1961) und Davis (1970) bei Hydra festgestellten Zellbrücken beobachtet. Bei anderen Hydrozoen, bei denen zum Teil ebenfalls synchrone Cnidoblastenentwicklung konstatiert wurde (Carré, 1974a), wurden allerdings auch keine Zellbrücken zwischen Cnidoblasten beobachtet (Bouillon \& Massin, 1974). Eine Deutung der synchronen Entwicklung ist daher bei diesen wie bei den Ocotocorallia vorerst nicht möglich.

\section{Die Mobilität der Cnidoblasten und die Reifung der Nesselkapseln}

Auf Mobilität der Cnidoblasten der Octocorallia lassen bereits die lichtmikroskopischen Befunde schließen, wonach im Ektoderm des Scapus ausschließlich Entwick- 
lungsstadien und in den Tentakelpinnulae ausschließlich reife Nesselkapseln vorkommen. Zumindest zwischen diesen beiden Regionen muß demnach ähnlich wie bei den Hydrozoen die Wanderung und - im vorliegenden Fall - die innere Differenzierung der Cnidoblasten und die Reifung der Nesselkapseln erfolgen. Beide Vorgänge stehen daher in Zusammenhang. Lichtmikroskopischen Untersuchungen zufolge (Schneider, 1900; Tardent \& Morgenthaler, 1966; Rich \& Tardent, 1969; Zumstein, 1973) wandern die Cnidoblasten der Hydrozoen nach der strukturellen Differenzierung der Cniden einzeln amöboid durch Interzellularspalten. Nach Aussagen zahlreicher Autoren wandern die Cnidoblasten ausschließlich im Ektoderm (u. a. Zumstein, 1973; Carré, 1974b; Herlands \& Bode, 1974), und zwar mit dem Pseudopodium voran und der Nesselkapsel im Schlepp (Kühn, 1914-1916; Campbell \& Marcum, 1980), wobei der Basalpol der Kapsel in Bewegungsrichtung zeigt (Hauenschild, 1957; Abb. 3). Daß die Cniden wandernder Cnidoblasten reifen, ist durch die histochemischen Untersuchungen an Hydrozoen von Burnett (1960), Lentz \& Barrnett (1961) und Günzl (1968) bekannt. Strukturell, d. h. elektronenmikroskopisch, liegen zu diesem Vorgang widersprüchliche Angaben vor. Nach Carré (1974c) sollen die Cniden der Siphonophoren in unreifem, teils sogar noch nicht vollständig differenziertem Zustand (noch fehlende Bewaffnung), ihr Ziel erreichen. Den Cnidoblasten, die die Autorin mit interstitiellen Zellen vergleicht, fehlen nach Carré's Darstellung (1974b, fig. 3) selbst nach der Wanderung noch die inneren und äußeren Strukturen des Cnidocils und die cnidenverankernden strukturellen Differenzierungen. Bei Campbell (1974), der bisher den einzigen wandernden Cnidoblasten mit Pseudopodien elektronenmikroskopisch abgebildet hat, ist das Cnidocil zumindest äußerlich in diesem Stadium zu erkennen. Wie Holstein (1981) kürzlich feststellte, sind auch die inneren, Kapsel und Cnidocil begleitenden Strukturen, weitgehend vor der Wanderung ausgebildet. Wir dagegen nehmen an, daß die in allen Stadien präsenten Centriolenkomplexe (vgl. Schmidt, 1981) - sollten die Cnidoblasten von Epitheloberflächenzellen abstammen - ähnlich wie bei den Spermien (Schmidt \& Zissler, 1979; Schmidt \& Höltken, 1980; Schäfer \& Schmidt, 1982) von normalen Flagellen stammend beibehalten und zur Basis des Cnidocils werden.

Allerdings zeigen die vorliegenden elektronenmikroskopischen Ergebnisse hinsichtlich der Wanderung ein etwaś differenzierteres Bild als die bisherigen Befunde. Bei den Alcyonarien sind dreí verschiedene Gruppen von Cnidoblasten zu unterscheiden, von denen zumindest aufgrund ihrer Entfernung vom Ort ihrer Genese anzunehmen ist, daß sie diesen, wie auch immer, verlassen haben. Nur in einem Fall deutet der strukturelle Befund auf aktives Wandern. Die weitgehend undifferenzierten, noch reichlich Ribosomen enthaltenden Cnidoblasten mit den kurz nach der Schlaucheinlagerung typisch kollabierten Nesselkapseln (Schmidt, 1981) sammeln sich an der Oberfläche des Scapusektoderms (Abb. 2, 4). Doch lassen weder ihre Form (keine Pseudopodien oder Zellausläufer), noch ihre innere oder äußere Struktur auf aktives Wandern schließen. Als erste innere Differenzierung treten in diesem Stadium die quergestreiften Fibrillen auf, die den "supportive rods" der Hydrozoencnidoblasten entsprechend von Holstein (1981) ebenfalls als erste cytoplasmatische Differenzierung sogar noch während der Wachstumsphase der Nesselkapsel erkannt wurden. Die unregelmäßige, teils quer zur Nesselkapsel bestehende Anordnung dieser Fibrillen deutet im Gegensatz zu ihrer späteren parallelen, schopfartigen Ausrichtung in aktiv wandernden Cnidoblasten nicht auf gerichtete Bewegung von Cnide oder Cnidoblast. Die im oberen Scapus massenhaft 
versammelten Cnidoblasten zeigen zwar schmale Zellausläufer, die aber eher durch die Reduktion des Cytoplasmas als durch amöboide Bewegung entstanden sein dürften. Obwohl solche Cnidoblasten, die eine dem reifen Zustand (s. u.) entsprechende Fibrillenanordnung am distalen Kapselpol noch nicht erkennen lassen, bereits in der Lage sind, noch innerhalb des Gewebes das typische, von Stereocilien umstandene Flagellum zu bilden, sprechen ihre engen Zellkontakte (Zonulae adhaerentes) gegen ein aktives Wandern einzelner Cnidoblasten (Carré, 1974b). An der Oberfläche des Ektoderms bringen einzelne Cnidoblasten, möglicherweise rein zufällig, ihre Cniden in Stellung (Carré, 1974c, Tafel 1). Schließlich sprechen dieses "frühreife" Verhalten, das in krassem Widerspruch zum mangelnden Reifegrad von Cnidoblast und Nesselkapsel steht, und die große Anzahl gegen eine aktive, individuelle Wanderung einzelner Cnidoblasten. Alles deutet vielmehr darauf hin, daß diese Cnidoblasten, wie auch die vorangegangenen Stadien, durch den laufenden Nachschub aus den Muskeltaschen im Gewebeverband passiv verschoben werden, wie von Shostak \& al. (1965) und vor allem von Campbell $(1967,1974)$ für Hydra postuliert. Auf diese Weise entstehen bei den Octocorallia Cnidoblasten- bzw. Cnidendepots, die in Form einer mehr oder weniger auffallenden Ektodermverdickung (Abb. 1a) unterhalb der Tentakelbasen noch relativ nah am Entstehungsort, jedoch relativ weit vom Einsatzort entfernt, angelegt werden. Die eigentliche Wanderung zum Einsatzort steht also noch bevor. Solche Cnidoblastendepots sind auch von Hydropolypen an entsprechender Stelle und bei den Hydromedusen, z. B. in Form der Nesselringe an den Tentakelbasen bzw. Manubrien, bekannt ( $u$. a. Hauenschild, 1957; Mergner, 1957). Im Gegensatz zu den vorliegenden Befunden beschreibt jedoch Carré $(1972,1974$ c) Cnidoblasten dieses Stadiums bei Siphonophoren als Wanderstadien, die sich von ruhenden lediglich durch die fehlenden speziellen Kontakte unterscheiden sollen. Die Autorin vergleicht diese Cnidoblasten, die ebenfalls unreife Nesselkapseln enthalten und nach dem Wandern massiert vorkommen, mit interstitiellen Zellen. Wir vermuten dagegen, daß es sich um den Alcyonariendepots entsprechende Cnidoblastenhaufen handelt, die bei den Siphonophoren mit auswachsenden Tentakeln möglicherweise wie bei Hydra und den Alcyonarien passiv verlagert werden und daher auch strukturell keinen Hinweis auf aktives Wandern ergeben.

Ein ganz anderes Bild zeigen hingegen die cytoplasmareichen Cnidoblasten in oberem Scapus und Tentakeln. Wie bisher ausnahmslos bei den Hydrozoen beschrieben, werden diese Cnidoblasten stets nur einzeln und im Gegensatz zu den vorher genannten mit unterschiedlich reifen Nesselkapseln angetroffen. Die von den Hydrozoen bekannte amöboide Bewegung ist unter anderem an dem am Óffnungspol der Kapsel gelegenen Schopf parallel verlaufender, quergestreifter Fibrillen zu erkennen (Abb. 8), die nach vollzogener Wanderung im reifen Cnidoblasten in nahezu entgegengesetzter Richtung radiär die Kapselöffnung umgeben und vor der Wanderung quer zur Kapsel angeordnet sind. Sollte die Kapsel, wie bei den Hydrozoen mehrfach beobachtet (Hauenschild, 1957; Günzl, 1971; Campbell, 1974), während der Wanderung mit der Basis voran geschleppt werden, so wäre die parallele Anordnung der Fibrillen und möglicherweise ihr Fehlen an der Basis auf diese Bewegungsrichtung zurückzuführen. Wie bereits von den älteren Autoren beobachtet (Kühn, 1914-1916), soll sich das vorangehende Pseudopodium an der Mesogloea festsetzen. Auf diese Weise entsteht bei den Hydrozoen der von Slautterback (1967) und Westfall (1970) beschriebene cnidomusculoepitheliale Zellkomplex, der bei den Anthozoen allerdings noch nicht nachgewie- 
sen wurde. Da er eindeutig in den häufig rein ektodermalen Tentakelpinnulae der Octocorallia fehlt, ist bei diesen auch an eine entgegengesetzte Ausrichtung der Cnide im wandernden Cnidoblasten zu denken. Die schweifartig ausstrahlenden quergestreiften Fibrillen könnten der Verankerung im Pseudopodium dienen und so die Kapsel nachziehen. Parallel zu den Veränderungen im Cnidoblasten vollzieht sich während der Wanderung die Reifung der Cnide. Diese ist im vorliegenden Fall lichtmikroskopisch an der abnehmenden Basophilie und elektronenmikroskopisch vor allem an der Aufhellung der Kapselmatrix zu verfolgen. Dieser Befund steht einerseits im Gegensatz zu einigen früheren lichtmikroskopischen Untersuchungen an Hydrozoen, denen zufolge die Reifung erst am Verbrauchsort erfolgen soll (Schneider, 1900; Ewald, 1915; Mergner, 1957), andererseits im Einklang mit den histochemischen Untersuchungen vor allem von Burnett (1960), Lentz \& Barrnett (1961) und Günzl (1968).

Günzl konnte bei Dipurena reesi sogar nachweisen, daß sich in völliger Ubereinstimmung mit unseren licht- bzw. elektronenmikroskopischen Befunden die Veränderungen während der Reifung allein auf die Matrix der Kapsel und nicht des Schlauches erstrecken. Letzterer bleibt nach Günzls (1968) Beobachtungen auch nach der Reifung im Gegensatz zur Kapselmatrix basophil, was ebenfalls auf eine unterschiedliche Zusammensetzung von Schlauch- und Kapselmatrix deutet (Schmidt, 1981). Im Gegensatz zu diesen Befunden sollen die Nesselkapseln bei Siphonophoren laut Carré (1974c) nicht nur am Ort ihres Einsatzes reifen, sondern sich sogar auch noch differenzieren, indem sie die zum Teil fehlende Schlauchbewaffnung erst hier anlegen. Umstritten ist auch der Zeitpunkt der sogenannten "Härtung" der Kapselstrukturen, die sich bei der elektronenmikroskopischen Bearbeitung bisher immer wieder an einer schlechten Durchdringung von Fixier- und Einbettungsmittel bemerkbar machte (Carré, 1974c; Holstein, 1981). Bei nahezu sämtlichen gelungenen Präparationen bzw. Darstellungen vollständiger Nesselkapseln handelte es sich bisher um unreife bzw. halbreife Nesselkapseln (Chapman, 1961; Burnett, 1971). Die Nesselkapseln der Octocorallia geben dagegen weder strukturell noch durch präparatorische Schwierigkeiten eine Härtung der Kapselstrukturen zu erkennen. Allenfalls kann in den bestehenden Fällen bei wandernden bzw. gerade eingewanderten Cniden die von Schneider (1900) beschriebene Geschmeidigkeit solcher Nesselkapselstadien erblickt werden, da die feuerbereiten, in Stellung gebrachten Cniden stets wohlgerundet und ohne irgendwelche Einbuchtungen beobachtet wurden.

\section{Der reife Cnidoblast}

Uber reife Cnidoblasten von Anthozoen haben wir nur sehr mangelhafte Kenntnisse. Ivester (1977) beschreibt bei der Cnidogenese der Octocorallia weder die Genese noch Details der reifen Cnidoblasten. Westfall (1965) hat bruchstückhaft über einige Strukturen von angeschnittenen Cnidoblasten anläßlich der Beschreibung der Nesselkapseln von Metridium senile (Actiniaria) berichtet. In toto sind wir daher nur über den Bau verschiedener Hydrozoencnidoblasten durch die Arbeiten von Lentz (1966), Slautterback (1967), Bouillon \& Levi (1967) und Westfall (1970) unterrichtet. Der Vergleich der Octocorallia-Cnidoblasten mit denen der Hydrozoen führt zunächst die keineswegs überraschende Tatsache vor Augen, daß die Cnidoblasten der Octocorallia wesentlich primitiver gebaut sind, handelt es sich doch um eine der ursprünglichsten Cnidaria- 
Gruppen (Schmidt, 1974; Schmidt \& Zissler, 1979). Die Cnidoblasten der Octocorallia lassen jedoch in verschiedenen Strukturen Anlagen erkennen, die in den Hydrozoencnidoblasten eine wesentlich kompliziertere Ausgestaltung erfahren haben. Dies betrifft neben dem sogenannten Cnidocil vor allem die Strukturen, die unserer Meinung nach im Gegensatz zu Mattern \& al. (1965), Slautterback (1967) und Westfall (1970) in keinem direkten kausalen Zusammenhang mit dem Explosionsvorgang stehen, sondern die Cnide direkt oder indirekt im Cytoplasma verankern. Rein äußerlich fehlen den Octocorallia-Cnidoblasten die engen Beziehungen und Kontakte, die die Hydrozoencnidoblasten zum Bestandteil eines komplizierten cnidomusculoepithelialen Zellkomplexes machen. Engere Kontakte nimmt der Cnidoblast der Octocorallia nur an der Ektodermoberfläche in Form der septierten Desmosomen auf, ein Kennzeichen sämtlicher Cnidaria-Epithelien (Buisson, 1970; King \& Spencer, 1979; Wood \& Kuda, 1980), so auch der Hydrozoencnidoblasten (Slautterback, 1967). Die bei Hydrozoen basalen Kontakte zu Epithelmuskelzellen oder Nervenzellen (Slautterback, 1967; Westfall, 1970) sind bei den Octocorallia nicht festzustellen. Entsprechend differieren die basalen, cnidenverankernden Strukturen. Anstelle der bei den Hydrozoencnidoblasten von den Stereocilien ausgehenden und basal in Form eines Stranges bis hin zu den speziellen Zellkontakten zu verfolgenden Mikrofilamente (Slautterback, 1967; Bouillon \& Levi, 1967; Westfall, 1970) haben die Octocorallia-Cnidoblasten einen querliegenden, fibrösen Ring an der Nesselkapselbasis. Die an der Basis und mitunter seitlich neben der Nesselkapsel wenig geordneten, quergestreiften Fibrillen halten wir für Kollagen (vgl. hierzu Meek, 1968). Sie erwiesen sich weniger durch ihre Struktur, als durch ihre apikale Position als analog zu den von Slautterback (1967) einfach "rootlets" genannten "stiff" (Hyman, 1940) oder "supportive rods" (Westfall, 1970; "baguettes secondaires" Bouillon \& Levi, 1967) der Cnidoblasten. Ähnlich wie diese umgeben sie distal die Nesselkapsel in radiärer Anordnung, ohne allerdings wie in den Hydrozoencnidoblasten den Centriolenkomplex bzw. das Flagellum einzuschließen (Abb. 17).

Den "supportive rods" der Hydrozoencnidoblasten entsprechend, liegen die quergestreiften Fibrillen mit ihren terminal verbreiterten Enden eng der Zellmembran an und können diese auch leicht vorwölben. Die in den wandernden Cnidoblasten beobachteten schweifartigen Ausläufer der quergestreiften Fibrillen entsprechen zwar den Darstellungen von Slautterbacks "rootlets". Da sie aber in den reifen Cnidoblasten offenbar nicht mehr vorkommen, handelt es sich möglicherweise um Genesestadien. Im Gegensatz zu den "rods" der Hydrozoen sind die quergestreiften Fibrillen der Octocorallia weder untereinander noch mit den Stereocilien verbunden, die bei den Octocorallia die stark fibrilläre Innenstruktur der Hydrozoenstereocilien vermissen lassen. Verbindungen zwischen Stereocilien und quergestreiften Fibrillen werden bei den Octocorallia höchstens durch Mikrotubuli hergestellt. Im Gegensatz zu den "rods" und den quergestreiften Fibrillen gleicht der fibröse Ring der Octocorallia-Cnidoblasten zwar weitgehend in der Struktur, aber keineswegs in Form und Position dem basalen, fibrösen Strang der Hydrozoencnidoblasten. Bei Aktiniencnidoblasten hat Westfall (1965) den fibrösen Ring ("circular fibers") nicht an der Basis, sondern apikal vorgefunden und den wesentlichen Unterschied zwischen dessen einfachen, zarten Fibrillen und den relativ starken, quergestreiften Fibrillen nicht erwähnt. Übereinstimmend mit den vorliegenden Befunden hat Westfall dagegen den eigenartig elektronenlichten Raum um die Nesselkapsel beobachtet, von dem wir annehmen, daß er in unmittelbarem 
Zusammenhang mit dem Explosionsvorgang, möglicherweise durch Bereitstellung eines bestimmten Mediums, steht. Dieser Raum liegt gewöhnlich zwischen Zellmembran und Cnide und wurde nie an der Spitze oder Basis beobachtet und ist daher möglicherweise kein Artefakt. Durch Westfall (1965) ist auch der einfache Bau des sogenannten "Cnidocils" der Anthozoen bekannt, der hiermit auch für die Octocorallia bestätigt wird. Da sich der Ciliarkonus in seiner Zusammensetzung, insbesondere der einfache Bau des Flagellums, einerseits so gut wie nicht von dem normaler flagellater Anthonzoenzellen unterscheidet (vgl. Lyons, 1973; Peteya, 1973, 1975; Mariscal \& Bigger, 1977; Schmidt \& Zissler, 1979), andererseits aber insbesondere die innere Struktur der Stereocilien, vor allem aber das Flagellum betreffend, erheblich vom komplexen Aufbau des Hydrozoencnidocils (Slautterback, 1967; Bouillon \& Levi, 1967; Westfall, 1970) abweicht, ist es kaum gerechtfertigt, bei den Anthozoen von einem Cnidocil zu sprechen, welche Funktion dieses auch immer haben mag. Die Zahl der Stereocilien, die hier bei den Octocorallia-Cnidoblasten mit 7 als normal zu bezeichnen ist, ist bei den Hydrozoencnidoblasten ebenfalls erhöht.

\section{Der Zerfall}

Der von Slautterback (1967) als Exocytose beschriebenen Ausstoßung der Nesselkapsel folgt, das lassen die vorliegenden Befunde zumindest sehr stark vermuten, auch die Abstoßung der Cnidoblasten. Nichts deutet, wie von Slautterback (1967) und von Westfall (1970) für die Hydrozoen erwogen, bei den Octocorallia auf längeren Bestand des Cnidoblasten. Der gegenteilige Fall würde dem von Campbell (1967) für Hydra postulierten Wachstumsmodell, nach dem an den Körperenden permanent Zellen verbraucht werden, widersprechen.

Die Nesselkapseln entstehen bei vielen Cnidaria ausschließlich im Ektoderm. Im vorliegenden Fall der Octocorallia wird dieser auch bei den Hydrozoen gesicherte Befund auffällig an der Grenze zwischen Ektoderm und Pharynx, einem bei den Anthozoen rein entodermalen Gebilde (Schmidt, 1970), durch den abrupten Abbruch der Cnidogenese im Bereich des Pharynx demonstriert. Frühere Berichte (Hadzi, 1909; Mergner, 1957; Burnett \& Lentz, 1960; Znidaric \& Lui, 1969), vor allem über das entodermale Wandern von Cnidoblasten, beruhen wahrscheinlich auf der Beobachtung phagocytierter Cniden bzw. Cnidoblasten (Burnett, 1961), wie hier bei den Octocorallia ausschließlich beobachtet.

Die phagocytierten Cniden geben durch ihre Stellung und durch das angelagerte myelin- und/oder lipidartige Material zu erkennen, daß sie unbrauchbar bzw. degeneriert sind. Durch die frühe Auflösung des gesamten Kapselinhaltes (einschließlich Schlauch und Propria) wird die Kapsel offenbar zunehmend eingedellt und verformt, was Chapmann \& Tilney (1959) als Fixierungsartefakt betrachteten. Als letzte Struktur bleibt die Sklera erhalten, die sich damit tatsächlich als offenbar härtester Kapselbestandteil erweist, wie bereits von Schneider (1900) beschrieben.

Danksagung. Die Autoren danken den Herren Professor Müller (Heidelberg) und Dr. T. Holstein (Zürich) für kritische Durchsicht des Manuskripts, Herrn Professor Storch für freundliche Materialbeschaffung und Durchsicht des Manuskripts. Die Arbeit wurde am Elektronenmikroskop des Lehrstuhls für Zellenlehre (Prof. Schnepf) und mit Unterstützung der Deutschen Forschungsgemeinschaft (DFG) durchgeführt. 


\section{ZITIERTE LITERATUR}

Achermann, J. \& Tardent, P., 1973. Untersuchungen zum Problem des Nematocytennachschubs bei Cladonema radiatum. - Revue suisse Zool. 80, 704-712.

Bouillon, J. \& Levi, C., 1967. Ultrastructure du cnidocil, de l'appareil cnidociliare, de l'appareil perinématocystique et du Cnidopode des nématocystes d'hydroides. - Am. Sci. nat. Zool. 9, 425-456.

Bouillon, J. \& Massin, C., 1974. La cnidogenèse. - Annis Soc. T. zool. Belg. 104, 7-38.

Buisson, B., 1970. Les supports morphologiques de l'intégration dans la colonie de Veretillum cynomorium. - Z. Morph. Tiere 68, 1-36.

Burnett, A. C., 1961. Growth factors in the tissues of Hydra. In: The biology of Hydra. Ed. by H. M. Lenhoff \& W. F. Loomis. Univ, of Miami Press, Coral Gables, Fla., 425-440.

Burnett, A. L., 1960. The nematocyst of Hydra. II The maturation of nematocysts in Hydra. - AnnIs Soc. r, zool. Belg. 90, 269-280.

Burnett, A. L. \& Lentz, T., 1960. The migration pathways of nematocysts in Hydra. - Annls Soc. r. zool. Belg. 90, 281-293.

Burnett, J. W., 1971. An Electron microscopic study of two nematocytes in the tentacles of Cyanea capillata. - Chesapeake Sci. 12, 67-71.

Campbell, R. D., 1967. Growth pattern of Hydra: Distribution of mitotic cella in H. pseudoligactis. Trans. Am. microsc. Soc. 86, 169-173.

Campbell, R. D., 1974. Cell movements in Hydra. - Am. Zool. 14, 523-535.

Campbell, R. D. \& Marcum, B. A., 1980. Nematocyte migration in Hydra: Evidence for contact guidance in vivo. - J. Cell. Sci, 41,33-51.

Carré, D., 1972. Etude du développement de cnidocystes dans le gastrozoide de Muggiaea kochi. C. r. hebd. Séanc. Acad. Sci, 275, 1263-1266.

Carré, D., 1974a. Formation, migration et maturation des nématoblastes et des nematocystes chez les siphonophores. I. Mise en évidence et formation des clones de nématocystes. - Annls Embryol. Morphogen. 7, 205-218.

Carré, D., 1974b. Formation, migration et maturation des nématoblastes et des nématocystes chez les siphonophores. II. Migration. - Annls Embryol. Morphogen. 7, 221-232.

Carré, D., 1974c. Formation, migration et maturation des nématoblastes et des nématocystes chez les siphonophores. III. Maturation des nématoblastes et des nématocystes. - Annls Embryol. Morphogen. 7, 233-242.

Chapman, G. B., 1961. The fine structure of the stenoteles of Hydra. In: The biology of Hydra. Ed. by H. M. Lenhoff \& W. F. Loomis. Univ. of Miami Press, Coral Gables, Fla., 131-151.

Chapman, G. B. \& Tilney, L. G., 1959. Cytological studies of the nematocysts of Hydra. I. Desmonemes, Isorhizas, Cnidocils and Supporting Structures. - J. biophys. biochem. Cytol. 5 , $69-78$.

Davis, L. E., 1970. Further observations on dividing and nondividing cnidoblasts in the regenerating isolates gastrodermis of Hydra. - Z. Zellforsch. mikrosk. Anat. 105, 526-537.

Ewald, A., 1915. Uber den Bau, die Entladung und Entwicklung der Nesselkapseln von Hydra und Porpita mediterranea, nebst einigen histologischen Bemerkungen über die letztere Form. Verh. naturh.-med. Ver. Heidelb. 16, 303-354.

Günzl, H., 1968. Über die Reifung der Nesselkapseln bei Dipurena reesi Vanucci. - Z. Zellforsch. mikrosk. Anat. 89, 509-518.

Günzl, H., 1971. Dipurena reesi (Hydrozoa). Wanderung der Cnidoblasten in den Rhizostolonen. Encyclopaedia Cinematographica, Göttingen.

Hadzi, J., 1909. Uber die Nesselkapselwanderung bei den Hydroidpolypen. - Arb. zool. Inst. Univ. Wien, 17, 65-94.

Hauenschild, C., 1957. Versuche über die Wanderung der Nesselzellen bei der Meduse von Eleutheria dichotoma. - Z. Naturf. 12, 472-477.

Herlands, R. L. \& Bode, H. R., 1974a. Nematocyte migration in Hydra, influenced by tissue polarity. - Nature, Lond. 248, 387-390.

Herlands, R. L. \& Bode, H. R., 1974b. Oriented migration of interstitial cells and nematocytes in Hydra attenuata. - Wilhelm Rouxs Arch. EntwMech. Org. 176, 67-88. 
Holstein, T., 1981. The morphogenesis of nematocytes in Hydra and Forskalia. - J. Ultrastruct. Res. $75,276-290$.

Hyman, L. A., 1940. The invertebrates Vol. 1: Protozoa-Ctenophora. McGraw-Hill, New York, 726 pp.

Ivester, M. S, 1977. Nematocyst differentiation in the anthozoon Renilla reniformis. -.. Trans. Am. microsc. Soc. $96,238-247$.

King, M. G. \& Spencer, A. N., 1979. Gap and septate junctions in the excitable endoderm of Polyorchis penicillatus. - J. Cell Sci, 36, 391-400.

Kühn, A., 1914-1916. Coelenterata Histologie. VII. Die Nesselorgane. - Bronn's Kl. Ord. Tierreichs, 2 (2), $22-26$.

Lentz, T. L. \& Barrnett, R. J., 1961. Enzyme histochemistry of Hydra. - J. exp. Zool. 147, $125-149$.

Lentz, T. L., 1965. The fine structure of differentiating interstitial cells in Hydra. $-\mathrm{Z}$. Zellforsch. mikrosk. Anat. 67,547-560.

Lentz, T. L., 1966. The cell biology of Hydra, Elsevier, Amsterdam, 199 pp.

Lyons, K. M., 1973. Collar cells in planula and adult tentacle ectoderm of the solitary coral Balanophyllia regia. - Z. Zellforsch. mikrosk. Anat. 145, 57-74.

Mariscal, R. N. \& Bitter, C. H., 1977. Possible ecological significance of octocoral epithelial ultrastructure. - Proc. int. Coral Reef Symp. 3, 127-133.

Mattern, C. F. T., Park, H. D. \& Daniel, W. A., 1965. Electron microscope observations on the structure and discharge of the sternothele of Hydra. - J. Cell Biol. 27, 621-638.

Meek, G. A., 1968. Apparent intracellular collagen synthesis. In: Cellstructure and its interpretation. Ed. by S. M. McGee-Russel \& K. F. A. Ross. Amold, London, 225-235.

Mergner, H., 1957. Die Ei- und Embryonalentwicklung von Eudendrium racemosum CAVOLINI. Zool. Jb. (Anat. Ontogenie Tiere) 76, 63-94.

Minasian, L. L. \& Mariscal, R. N., 1979. The occurrence of cnidoblasts in different regions of a sea anemone, Haliplanella luciae (Verill). - The 4th int. Coelenterate Conf., Interlaken, Poster (Abstracts).

Moroff, T. H., 1909. Entwicklung der Nesselzellen bei Anemonia. Ein Beitrag zur Physiologie des Zellkerns. - Arch. Zellforsch. 4, 142-161.

Peteya, D. J., 1973. A possible proprioceptor in Cerianthopsis americana. - Z. Zellforsch. mikrosk. Anat. 144, 1-10.

Peteya, D. J., 1975. The cilliary-cone sensory cell of anemones and cerianthids. - Tissue Cell 7 , 243-252.

Rich, F. \& Tardent, P., 1969. Untersuchungen zur Nematocyten-Differenzienung bei Hydra attenuata. - Revue suisse Zool. 76, 779-787.

Schäfer, W. \& Schmidt, H., 1982. Die Struktur und Genese der Anthozoenoocyten. - In Vorbereitung.

Schmidt, H., 1970. Anthopleura stellula and its reproduction by transverse fission. - Mar. Biol. 5 , $245-255$.

Schmidt, H., 1974. On the evolution in the Anthozoa. In: Proceedings of the 2nd International Coral Reef Symposium. Great Barrier Reef Comm., Brisbane, 1, 533-560.

Schmidt, H., 1981. Die Cnidogenese der Octocorallia (Anthozoa, Cnidaria): I. Die Sekretion und Differenzierung von Kapsel und Schlauch. - Helgoländer Meeresunters. 34, 463-484.

Schmidt, H. \& Zissler, D., 1979. Die Spermien der Anthozoen und ihre phylogenetische Bedeutung. - Zoologica, Stuttg. 129, 1-97.

Schmidt, H. \& Höltken, B., 1980. Peculiarities of spermatogenesis und sperm in anthozoa. Development and cellular biology of coelenterates. Ed. by P. Tardent \& R. Tardent. Elsevier, Amsterdam, $53-73$.

Schneider, K. C., 1900. Mitteilungen über Siphonophoren. V. Nesselzellen. - Arb. zool. Inst. Univ. Wien $12,133-243$.

Shostak, S., Patel, G. \& Burnett, A. L., 1965. The role of mesogloea in mass cell movement. - Devl. biol. $12,434-450$.

Skaer, R. J., 1973. The secretion and development of nematocysts in a siphonophore. - J. Cell Sci. $13,371-393$

Slautterback, D. B., 1961. Nematocyst development. - In: The biology of Hydra. Ed. by H. M. Lenhoff \& W. F. Loomis. Univ. of Miami Press, Coral Gables, Fla. 77-129. 
Slautterback, D. B., 1967. The cnidoblast-musculoepithelial cell complex in the tentacles of $H y d r a$. - Z. Zellforsch. mikrosk. Anat. 79, 296-318.

Slautterback, D. B. \& Fawcett, D. W., 1959. The development of the cnidoblasts of Hydra. - J. biophys. biochem. Cytol. 5, 441-452.

Tardent, P. \& Morgenthaler, U, 1960. Autoradiographische Untersuchungen zum Problem der Zellwanderung bei Hydra attenuata. - Annls Soc. r. zool. Belg. 90., 281-293.

Tardent, P., Rich, F. \& Schneider, V., 1971. The polarity of stenothele differentiation in $H y d r a$ attenuata Pall. - Devl. Biol, 24, 596-608.

Weber, G., Honegger, T. \& Tardent, P., 1978. Neuorientierung der Nesselzellwanderung bei Hydra attenuata PALL. durch transplantierte Tentakel. - Revue suisse Zool. 85, 768-774.

Weill, R., 1934. Contribution al l'étude des cnidaires et des leurs nématocystes. - Trav. Stn zool. Wimereux 10-11, 1-701.

Westfall, J., 1965. Nematocysts of the sea anemone Metridium. - Am Zool, 5, 377-393.

Westfall, J., 1970. The nematocate complex in a hydromedusan, Gonionemus vertens, - Z. Zellforsch. mikrosk. Anat. 110,457-470.

Wood, R. L. \& Kuda, A. M., 1980. Formation of junctions in regenerating Hydra: Septate junctions. J. Ultrastruc. Res. 70, 104-117.

Yanagita, T. M. \& Wada, T., 1959. Physiological mechanisms of nematocyst responses in sea anemone. - Cytologica 24, 81-97.

Znidaric, D. \& Lui, A., 1969. Redifferentiation of gland cells in Hydra and further development of interstitial cells arising from them. - Wilhelm Rouxs Arch. EntwMech. Org, 162, 374-383.

Zumstein, A., 1973. Regulation der Nematocyten-Produktion bei Hydra attenuata. - Wilhelm Rouxs Arch. EntwMech. Org. 173, 294-318.

Zumstein, A. \& Tardent, P., 1971. Beitrag zum Problem der Regulation der Nematocytenproduktion bei Hydra attenuata. - Revue suisse Zool. 78, 705-714. 